\title{
UPDATED METHOD OF APTITUDE TO SUSTAINABLE URBAN DEVELOPMENT FOR INCLUDING GREEN INFRASTRUCTURE
}

\author{
JOSÉ LUIS MIRALLES I GARCIA \& VICENT JESÚS ALTUR GRAU \\ Department of Urban Planning, Polytechnic University of Valencia, Spain
}

\begin{abstract}
The research group UDR F. Eiximenis of Dpt of Urban Planning of Polytechnic University of Valencia, developed in 1992 the Method of Aptitude to Sustainable Urban Development. The method allows the identification of more or less adequate rural zones of Valencia region to transform for urban uses. The Valencia country is a Mediterranean landscape that is characterized by a mosaic of diverse rural and urban uses. The method is based on applying the concept of aptitude as a synthesis of the concepts of capacity and vulnerability of the territory to the residential, industrial and strategic public facilities. The method uses GIS technology as a tool for generating maps of adequate zones for uses with an analysis based on objective reasons that explain the outcome. Explicitly avoiding evaluation based on any types of weighted average of heterogeneous values of variables. The method has been applied in the assessment of environmental impacts caused by urban development in Valencia until today. Now arises the European policy to implement the concept of green infrastructure. The current planning and territorial policy in Valencia establishes the need to identify green infrastructure as a first step in the urban planning processes. The present paper develops a proposal for updating the method to sustainable urban development incorporating the concept of green infrastructure.
\end{abstract}

Keywords: green infrastructure, management natural resources, management territorial risk, regional planning, sustainable urban development.

\section{INTRODUCTION}

Our research team, UDR F. Eiximenis of Polytechnic University of Valencia, developed in 1996 a method for evaluating the greater or less aptitude of the territory to urban uses [1-3]. This method was a result of Agreement Collaboration between our team and the Conselleria d'Obres Públiques, Urbanisme i Transports of the Generalitat Valenciana (regional government).

The Method of Aptitude to Sustainable Urban Development (onward method ASUD) has been used for preparing environmental assessments in the process of drafting documents to urban planning.

In 2000, Spain sign the European Landscape Convention promoted by Council of Europe [4]. In 2004, regional government of Valencia approved the first Law about regional planning, which introduces landscape planning and management. After, the convention was ratified by Spain in 2007. This new paradigm introduces new variables to evaluate uses on territory.

In 2013, European Commission sends a communication to the European Parliament to introduce Green Infrastructure concept in Regional Policy [5]. Also, this new concept introduces other vision to evaluation and planning uses on territory. 
Our team is in process to update the method ASUD to integrate the new paradigms. This paper explains the results of initial studies about conceptual integration.

\section{THE METHOD OF APTITUDE TO SUSTAINABLE URBAN DEVELOPMENT (ASUD)}

\subsection{Basic concepts}

It is necessary to explain any essential idea to understand the method and its update.

First of all, we must intend to ensure transparency in the cause-effect relationships that justify the conditions of use in the territory. That is, if after analysis it is proposed any conditions to implement any urban use in any zone, it should be clear why, must be clear the causes which justify the result. Accordingly, the method avoids combining mathematical indicators of heterogeneous variables to produce a single final indicator. In this case, the end result usually has no meaning because it is not consistent mathematically. That is, you cannot add apples and oranges and, if added together, the result is meaningless.

The method aims at analyzing what are the best locations for new urban uses on rural land. As you can see in Figure 1, the analysis is based on three concepts: capability, vulnerability and aptitude.

We define capability, or land capability to urban uses, as the appropriateness of the ground as a physical support for different urban uses. In function of physical characteristics, the ground or spatial zone can be more or less appropriate to support one or other urban use. In this concept, we consider only physical characteristics necessaries to support urban use. We do not consider, in this concept, possible impacts or transport conditions (accessibility). Capability considers land characteristics that affect the technical and economic urban construction process and urban activities planned for those areas.

We define vulnerability, or land vulnerability to urban uses, as the level of potential environmental impacts that may occur if a particular urban use is introduced in that zone. So this concept considers the environmental impacts produced if society introduce a particular urban use in a particular rural zone.

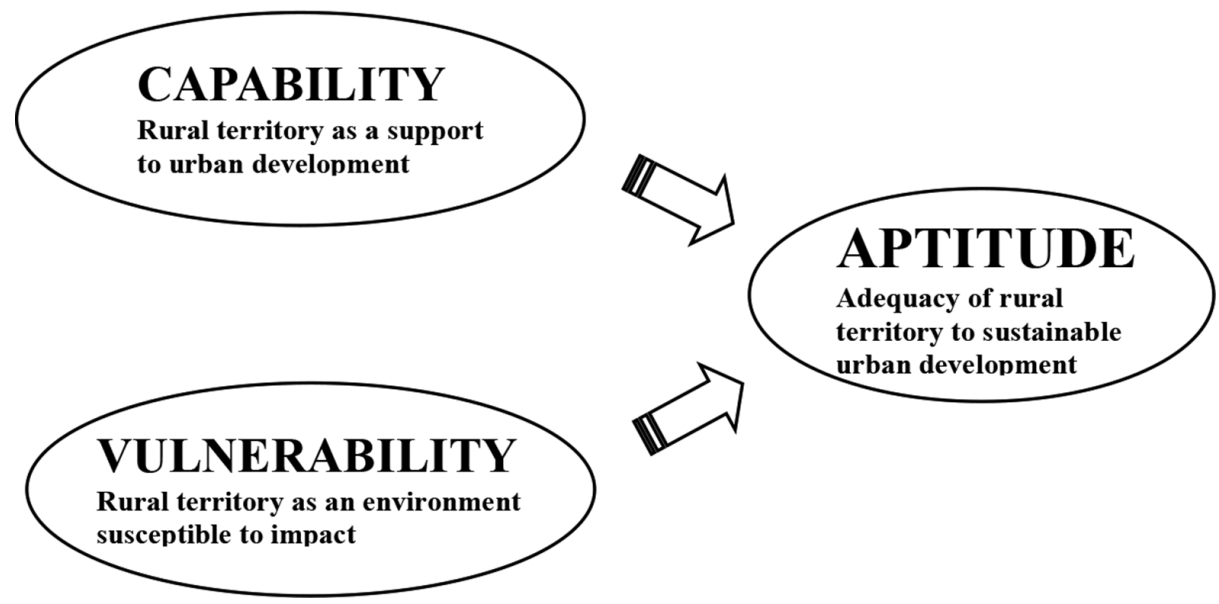

Figure 1: Aptitude as a synthesis of capability and vulnerability to sustainable urban development. 
Of course, the most suitable zones to locate it a particular urban use are those areas will simultaneously have higher capacity and lower vulnerability to such urban use. We define this characteristic as an aptitude. So the aptitude is the synthesis of capability and vulnerability. Each homogeneous zone of rural territory will have an aptitude to each urban use.

\subsection{Urban uses to consider}

The method is designed for use in the process of elaboration of municipal urban plans as part of the analysis of the environmental assessment. The basic uses usually consider the following:

1. General urban uses: Predominantly, residential use with a mixture of tertiary uses, stores, industry compatible with residential uses are compatible with low-level risks.

2. Hazardous industrial uses: In this case, the security criteria at the territorial risks are more rigorous.

3. Strategic uses: Hospitals, police, fire station and, in general, absolutely necessary use in emergencies. These uses should be fully operational in an emergency and therefore safety must be total.

\subsection{Mapping environmental units}

We can map territorial zones with the same environmental characteristics to evaluate the capability and vulnerability of each zone for each urban use. The regional government manages a territorial data base: Territorial Information System (SIT) [6]. Also manages the Spatial Data Infrastructure of Valencian Community, TERRASIT [7]. In SIT, you can obtain thematic cartography of different territorial variables in digital format with original scale 1:50.000.

\subsubsection{Mapping capability}

In order to mapping capability, we will consider two type of variables: physical conditions of ground to cement building and civil works and risks.

In particular, for region of Valencia, physical variables that can condition the construction of buildings are the slope and lithology. For example, gypsum zones are not adequate to cement building. About the risks, in our country the main risks are the risk of flood and landslide risk.

Each variable of capability can present one of the following three situations:

- Situation A. The variable does not present technical-economic limitations to urbanization and building. Therefore it is possible urbanize and building the area. In this case, the urban development costs are inside normal values.

- Situation B. The variable presents limitations to urbanize the area but can be overcome. The correction of these limitations produces a higher cost of urbanization. For example, if we have a zone with a medium slope or flood risk low water level, it is possible to urbanize and correct technical problems. Of course, the correction implies a higher cost of urbanization.

- Situation $C$. The variable presents limitations to urbanize the area and technical correction is impossible, too much costly or generate potential catastrophic situations. For example, 
in our country, it is very costly to build when the slope is greater than $18 \%$. In this case, the zone should not be urbanized by technical-economic limitations. A particular case is especially important that is corresponding to potential catastrophic situations because of the magnitude of the risk of flooding or landslides.

As we have four variables, we can generate four maps with situations A, B or C for each variable. And also we can superimpose the maps by GIS and obtain a capability map with zones without technical limitations to urbanize (all variables are in situation A), zones with overcome technical limitations (at least one variable in situation B but any variable in situation C) and zones with potential catastrophic risks or too much costly to urbanize (at least one variable in situation C). The system allows to identify the situation of each zone and the cause which justifies it. You can see an example of application in Fig. 2.

\subsubsection{Mapping vulnerability}

In order to mapping vulnerability, we will consider two types of variables: environmental values and protected areas.

In particular, for region of Valencia, the variables of environmental values that are included in protected areas are agrological capacity, aquifer vulnerability to pollution and vegetation cover. In addition, it exists a large list of protected areas because of different environmental values as beaches and dunes, humid zones, rivers, forests ... and also unprotected areas but have values that justify conservation (environments of interest).
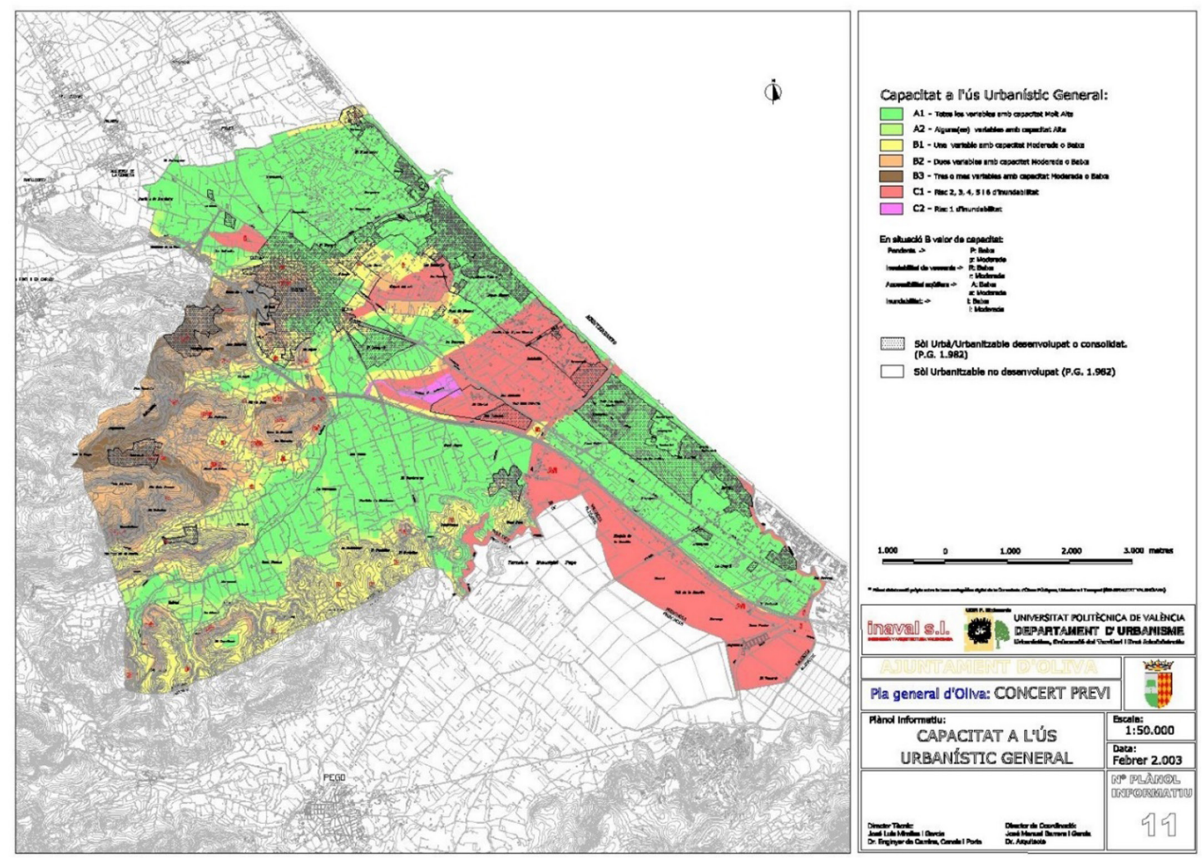

Figure 2: Capability map for municipality of Oliva (Valencia), 2003. Green for situation A. Ochres for situations B. Reds for situations C. 
The objective includes all environmental variables in this category that can be considered as natural resources. We consider all natural assets as natural resources that produce valued goods and services to the society. All natural resources that are part of ecological footprint are included in the variables of vulnerability. It is understood that not all the natural territory produces valued goods and services or the goods and services that produces are not significant.

Usually, when the society promotes an urban development, it produces an irreversible transformation from rural uses to urban uses. Consequently, natural resources in land surface are destroyed and replaced by urban uses. However there may be some unusual exceptions. For example, when a little forest is preserved into the new urban area.

Vulnerability is a measure of the degree of destruction of natural resources when urban development takes place. From this point of view, we can again find three situations (you can see in Fig. 3 an example of application):

- Situation A. In this case, the urbanization of the zone doesn't suppose the destruction of any valued natural resource or the significant alteration of any environmental variable. Therefore, in these cases, no type of environmental limitation to the urbanization exists.

- Situation B. In this case, the urbanization produces or could produce significant alterations in certain environmental variables but these alterations can be corrected. Therefore, no irreversible destruction of environmental values occurs. It is, for example, the case of potential contamination of aquifers due to pollutant solids or liquids.

- Situation C. Finally, in this third situation, the urbanization supposes the irreversible destruction of environmental known values. Note you that urbanization of rural zone almost

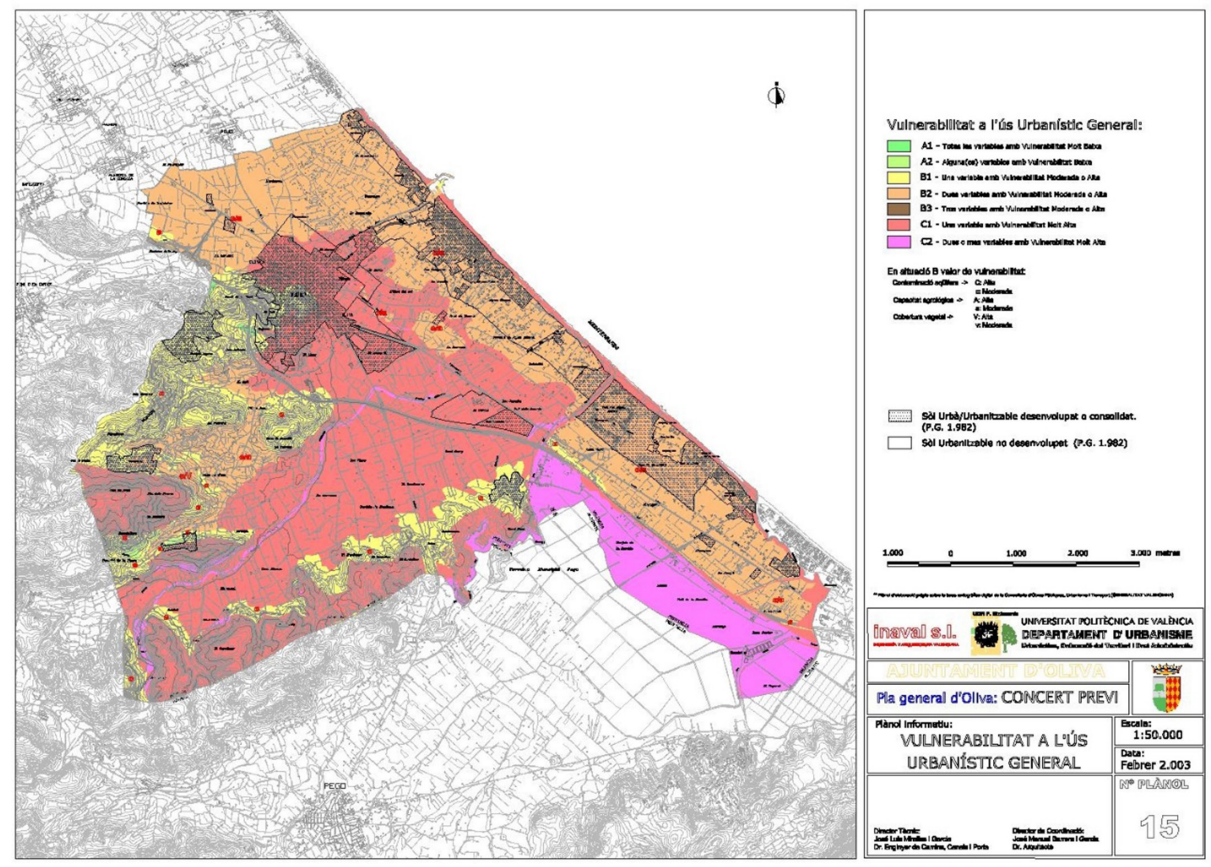

Figure 3: Vulnerability map for municipality of Oliva (Valencia), 2003. Green for situation A. Ochres for situation B. Reds for situation C. 
always produces the destruction of pre-existing rural uses and its replacement to urban uses.

It is important remember that in both analysis of capability and vulnerability there are direct cause-effect relationships between variables and use conditions. When the variables of capability or of vulnerability in any zones give rise to a certain situation (A, B or C), we identify the situation of each homogeneous zone to any urban use in an objective way.

\subsubsection{Mapping aptitude}

The more appropriate zones to locate its certain use will be those zones with better capability and minimal vulnerability for that use. Aptitude possible situations occur as a combination of the scenarios of capacity and vulnerability as you can see in Table 1 .

As you can see in Figure 4, the aptitude map shows objectively zones more or less suitable to locate it an urban use and allows to show directly and clearly the conditions of territory from urbanization or urban expansion.

The possible situations are:

- SL: Without Limitations (in Spanish 'Sin Limitación'). In this situation we do not have any limitations either punt of view of capability or vulnerability.

- A (TL): Zone apt to urban use. The zone has technical limitations or risks limitations but they can be corrected. Probably urbanizations costs will be higher.

- A(EC): Zone apts to urban uses. The zone has environmental conditions but environmental impacts can be correct.

- A (TL \& EC): Zone apts to urban uses. The zone has technical limitations and environmental conditions. Both limitations can be correct.

- DES: Urban development inadvisable in these zones (in Spanish 'Desaconsejable'). These cases take place when the urban development implies the destruction of environmental known values. They correspond to the combination of capability type A and B, with vulnerability type $\mathrm{C}$ that identifies the zones where the urbanization supposes a development economically not sustainable. The economic development is not compatible in these cases with the protection of the environment. This combination corresponds to situations of conflict between economic development and environment. The urban development in this zones is inadvisable if it is wanted to make prevail a sustainable development. Although this doesn't mean that the economic development doesn't take place since there is a possibility that urban use is necessary and with no other location alternative. In these situations, the decision on their urbanization is a decision fundamentally political.

Table 1: Aptitude matrix.

\begin{tabular}{lccl}
\hline \multicolumn{4}{c}{ APTITUDE } \\
\hline CAPABILITY & A & B & C \\
\hline A & SL & A (EC) & DES \\
B & A (TL) & A (TL \& EC) \\
C & \multicolumn{4}{c}{ NP } \\
\hline
\end{tabular}



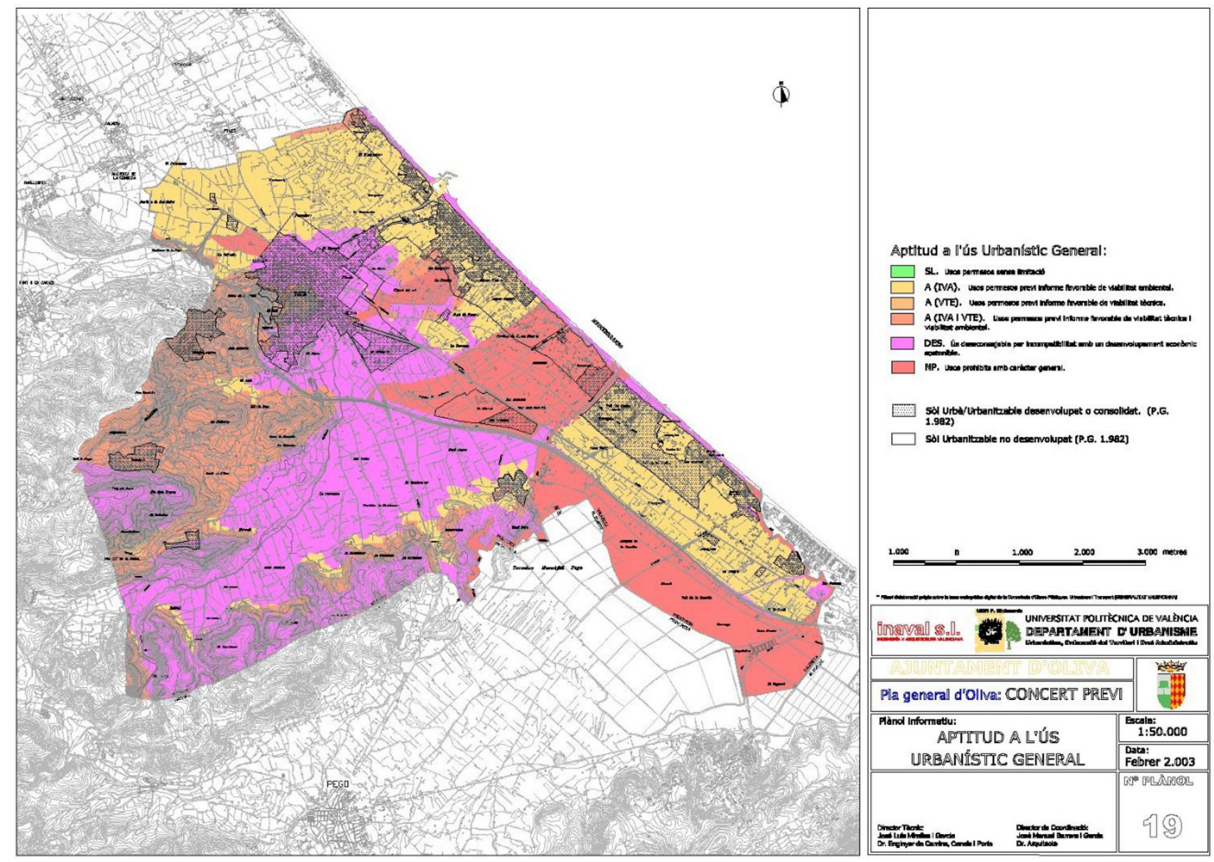

Figure 4: Aptitude map for municipality of Oliva (Valencia), 2003. Ochres colours, zones with some variable in situation B. Red colours, some colours in situation C.

- NP: Urban use is not allowed (in Spanish 'No Permitido'). In this case, urban use must be prohibited. These cases correspond to situations in which the urbanization is going to generate situations of catastrophe. For example, zones with severe risks of flooding. Nevertheless, the change in the physical conditions of risk will suppose a change in the situation of the zones concerned. For example, public works to increase safety from floods. In fact, this change also produces a change of capability's zone and capability map.

The aptitude map is obtained, by GIS, by superimposing maps of capacity and vulnerability. In any case, capability, vulnerability and aptitude maps are 'spots' maps, that is, a map of zones with different characteristics. They are not a network of zones necessary to connect between them.

\section{GREEN INFRASTRUCTURE CONCEPT}

In communication from Commission to the European Parliament, COM (2013) 249 final, Green Infrastructure (GI) - Enhancing Europe's Natural Capital [8], is defined green infrastructure as a strategically planned network of natural and semi-natural areas with other environmental features designed and managed to deliver a wide range of ecosystem services. It incorporates green spaces (or blue if aquatic ecosystems are concerned) and other physical features in terrestrial (including coastal) and marine areas. On land, GI is present in rural and urban settings.

This definition is very broad. The elements of green infrastructures deliver ecosystem services and are natural and semi-natural areas and other environmental features. So, the 
territorial elements of ecological footprint are a part of green infrastructure but are not the only ones. In addition, GI is present in rural and urban areas. This implies their study at different scales of analysis and planning: a regional scale for rural areas and an urban scale for urban areas. Finally, green infrastructure is a network, that is, a combination of territorial elements connected between them by corridors.

Regional government of Valencia develop this concept in last law about urban and regional planning, specifically in Regional and Urban Planning and Landscape Act of 2014 [9]. This Law defines the green infrastructure as a territorial system integrated by: spaces with more relevant environmental, cultural, agricultural and landscape value; critical areas where transformation implies risks or environmental costs; and the network of ecological corridors and functional connections between the above elements.

On the other hand, since 2011 urban planning in Valencian Country must apply the Valencian Territorial Strategy. This is a strategic document to orient or condition urban planning. So, in addition, law stablish a list of green infrastructure elements:

- Natura 2000 Network (at the moment this network occupies 36\% of territory)

- Protected areas by Valencian Acts

- Protected areas by international and Spain state rules

- Humid areas and aquatic ecosystems

- Marine waters associated to coastal ecosystems identified in Valencian Territorial Strategy

- Coastal areas with environmental and cultural interest identified in Valencian Territorial Strategy

- Public forests or private forests with public interest

- Agricultural areas with high quality because of different causes (productivity, safety from risks, landscape, original products)

- High quality landscapes identified in Valencian Territorial Strategy

- Spaces with high cultural value

- Critical areas because of natural and artificial risks identified in Valencian Territorial Strategy

- Other areas identified in urban and regional planning to integrate in green infrastructure network.

\section{INTEGRATION OF GREEN INFRASTRUCTURE IN APTITUDE TO SUSTAINABLE URBAN DEVELOPMENT METHOD}

In this situation, we can improve regional analysis of aptitude to integrate some variables of green infrastructure. Particularly, we can introduce in vulnerability map the following variables:

- Landscape milestone

- Visual opening

- Hydrological network

The landscape milestones add to vulnerability the territorial elements that are referent for skyline from different point of view.

Visual opening consists of those areas or vantage points for observing the landscape milestones. 


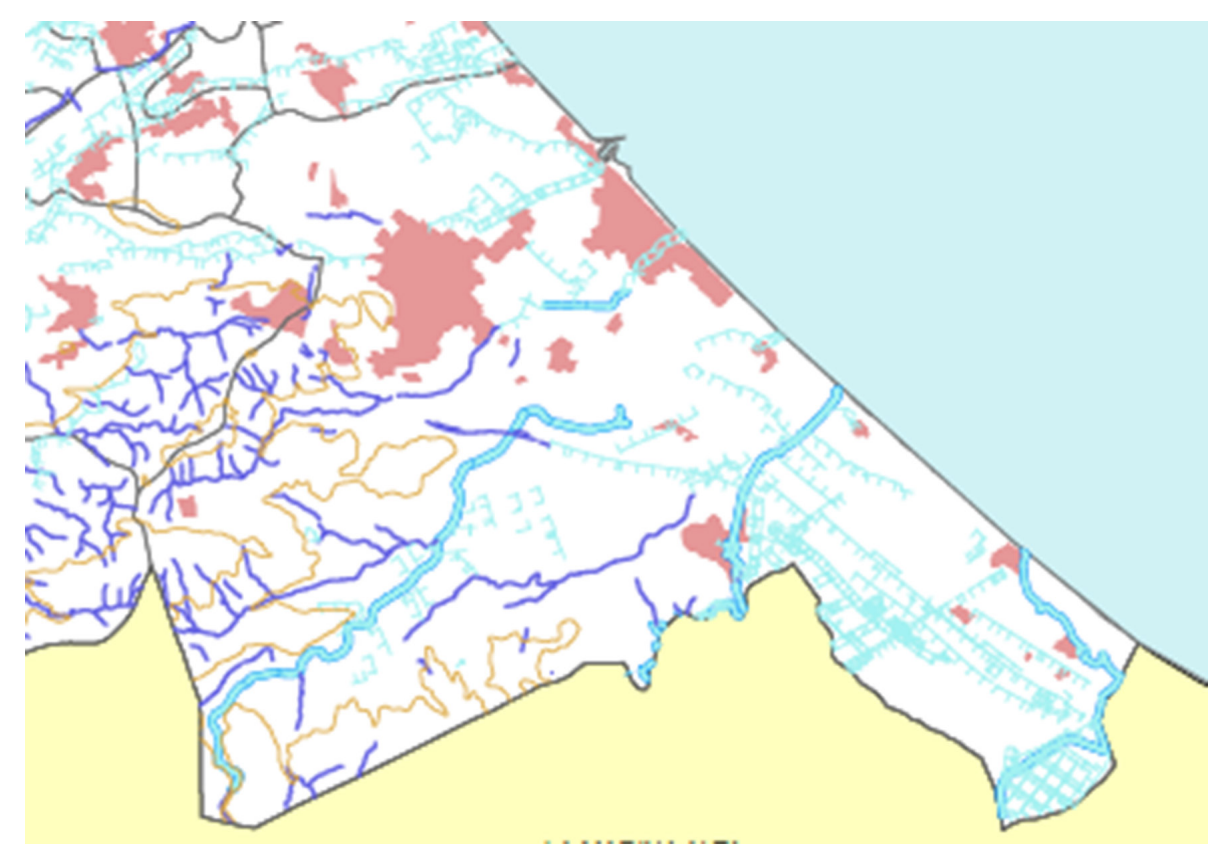

Figure 5: Hydrological network in Oliva (Valencia), blue lines.

Hydrological network is a natural network, often protected, widespread throughout the territory that allows us to establish a network of ecological corridors that connect most areas. In Figure 5 you can see the hydrological netword in municipality of Oliva. Note you that Valencia have a Mediterranean climate. Usually, hydrological network is dry and only carries water when it rains. This hydrological network is very important because, although rarely rains, the rain can drop large amounts of water which must flow through the channels of the gullies to prevent flooding.

Thus, we can complete the aptitude method to determine the green infrastructure, at the regional level, prior to making any decision on urban development. At the moment, we are testing modified method in the region of La Safor (Valencia).

In any case, will be necessary complete green infrastructure in urban areas. This implies urban scale analysis with other analysis and design methodologies additionally to aptitude method.

\section{CONCLUSIONS}

We can note the following conclusions:

- The aptitude method to sustainable urban development, applied in different studies since 1996, has proved to be useful to identify, based on objective causes, more or less suitable land areas for urban development with sustainability criteria.

- The new paradigms of the landscape and green infrastructure make it necessary that the method be reviewed and actualize considering its.

- From the point of view of landscape variables, it is possible introduce new variables as a landscape milestones and view shed. 
- From the point of view of the green infrastructure it is possible incorporate the new variable of the hydrological network as an ecological corridor.

- Aptitude method is valid to regional analysis of green infrastructure. To complete the green infrastructure at urban scale will be necessary apply other methods and tools.

- At present, the modified method is in testing phase in regional zone of La Safor (Valencia).

\section{REFERENCES}

[1] Miralles i Garcia et al., Una metodología de análisis y gestión del suelo rural para un desarrollo urbanístico sostenible. VII Congreso Iberoamericano de Urbanismo. Región y Calidad sostenible, Gobierno de Navarra: Pamplona (Spain), pp. 375-390, 1996.

[2] Miralles i Garcia, J.L. \& Altur Grau, V.J., Applied methodology in GIS support fort the definition of territorial ability to sustainable development. Environmental Challenges in an Expanding Urban World and the Role of Emerging Information Technologies, eds J.R. Machado \& J. Ahern, Nacional Centre for Geographical Information: Lisbon, pp. 179-188, 1997.

[3] Miralles i Garcia, J.L., An operative proposal for the implementation of the concept of sustainability in urban development. 2nd International Seminar Conservation and Urban Sustainable Development. A Theoretical Framework, Federal University of Pernambuco: Recife, pp. 195-206, 1999.

[4] European Landscape Convention, Council of Europe, available at http://www.coe.int/ en/web/landscape

[5] European Commission, available at http://ec.europa.eu/environment/nature/ecosystems/index_en.htm

[6] Generalitat Valenciana, available at http://www.citma.gva.es/web/sistema-de-informacion-territorial

[7] Generalitat Valenciana, available at http://terrasit.gva.es/

[8] Communication from the Commission to the European Parliament, the Council, the European Economic and Social Committee and the Committee of the Regions. Green Infrastructure (GI) - Enhancing Europe's Natural Capital. SWD (2013) 155 final, available at http://ec.europa.eu/environment/nature/ecosystems/docs/green_infrastructures/1_EN_ACT_part1_v5.pdf

[9] Llei 5/2014 d'Ordenació del Territorio, Urbanisme i Paisatge de la Comunitat Valenciana, available at www.citma.gva.es/ca/web/planificacion-territorial-e-infraestructuraverde 